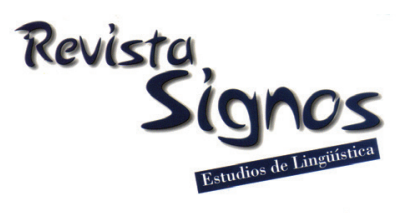

\title{
Funciones estratégicas de las redes de metáforas en torno a 'socialismo': Un análisis interaccional del discurso político de Hugo Chávez ${ }^{1}$
}

\author{
Strategic functions of metaphor networks on political discourse: An \\ Hugo Chavez interactional discourse analysis
}

\author{
Mercedes Duarte \\ Universidad Central de Venezuela \\ VENEZUELA \\ edyris.duarte@yahoo.es
}

Recibido: 23-V-2014 / Aceptado: 8-VII-2015

\section{Resumen}

Las redes de metáforas cognitivas son un recurso pragmático del discurso de amplia difusión en el ámbito político, como se colige de los estudios de Chumaceiro (2004), Adrián (2009, 2010) y Duarte (2011, 2013). En Duarte (2013) se explican las redes de metáforas en el discurso político, empero, no se discuten los aspectos relacionados con sus funciones estratégicas. Por ello, el propósito de este artículo es describir las funciones de las redes de metáforas cognitivas en torno a la palabra socialismo en el discurso del ex presidente Hugo Chávez. Se eligió un marco teórico mixto integrado por: la lingüística cognitiva (Lakoff \& Johnson, 2007) para el reconocimiento inicial de las metáforas simples; por el aporte lingüístico de Halliday y Hasan (1976), McCarthy (1990) y la Lingüística Sistémica Funcional de Halliday (1994), para reconocer las redes de metáforas y sus funciones; y por el Análisis Interaccional del Discurso de Bolívar (2007), para integrar los enfoques cognitivos y lingüísticos en el análisis. El corpus estuvo conformado por cuatro emisiones del programa Aló Presidente del año 2005. Se procedió, primero, con la identificación de las metáforas simples; luego se reconocieron las redes de metáforas; y finalmente, se detectaron las funciones discursivas de las redes. Los resultados permitieron reconocer tres funciones estratégicas, a saber: función representacional; función interpersonal y función metadiscursiva. Se concluye que las tres funciones están presentes de manera concomitante y articulada entre sí, y que están al servicio de los propósitos comunicativos identificables con el emisor.

Palabras Clave: Funciones estratégicas, redes de metáforas, discurso político, análisis interacciónal del discurso. 


\begin{abstract}
Cognitive metaphor networks are a pragmatic discourse resource widely used in the political realm, as inferred from the studies by Chumaceiro (2004), Adrián (2009, 2010) and Duarte (2011, 2013). Duarte (2013) explains metaphor networks in political discourse, but he does not discuss its functions. Therefore, the aim of this article is to describe cognitive metaphor network functions involving the word 'socialism' in president Hugo Chavez's discourse. For this purpose, a mixed theoretical framework was considered. This framework was shaped by (1) cognitive linguistics (Lakoff \& Johnson, 2007) in order to facilitate initial metaphor recognition; (2) Halliday \& Hasan (1976), McCarthy (1990) and Systemic Functional Linguistics by Halliday (1994) for metaphor networks and function detection; and (3) Interactional Discourse Analysis (Bolívar, 2007) to integrate cognitive and linguistic approaches in the analysis. The corpus consisted of four broadcasts of the television program Aló Presidente in 2005, and the procedure was as follows: simple metaphors were identified initially; then, metaphor networks recognition was carried out. It was possible to identify three functions of networks: representational, interpersonal, and metadiscoursive functions. It is concluded that the three functions are concurrent and coordinated with each other and serve communicative purposes that are identifiable with the speaker.
\end{abstract}

Key Words: Strategy functions, metaphor networks, political discourse, Interactional Discourse Analysis.

\title{
INTRODUCCIÓN
}

El estudio de las redes de metáforas cognitivas es un campo de investigación muy rico dentro de los estudios lingüísticos y del discurso cuya exploración comenzó hace relativamente pocos años, como lo confirman Chumaceiro (2004), Adrián (2009, 2010) y Duarte (2011, 2013), que son de las primeras investigaciones sistemáticas concentradas en el estudio de las redes de metáforas en el discurso político. Buena parte de los estudios lingüísticos sobre metáforas descansa sobre la contribución de Lakoff y Johnson (2007), por ser ellos quienes inauguraron los estudios de las metáforas, no como fenómenos retóricos para la persuasión o el embellecimiento del lenguaje, sino como mecanismos de la cognición, de la experiencia y de la comprensión intersubjetiva de dicha experiencia. Sin embargo, estos autores aportaron poco acerca de las redes de metáforas, porque se dedicaron principalmente a la descripción estructural de las metáforas simples y a su explicación como objetos lingüísticos de la cognición, lo cual dejó por fuera cuestiones como las redes de metáforas y sus usos estratégicos en el habla.

Las redes de metáforas son recursos pragmáticos de la lengua que se utilizan de manera extendida en el en el discurso político, porque al igual que las metáforas simples (Chilton \& Ilyin, 1993; Chumaceiro, 2004; Moreno Lara, 2005; Aponte Moreno, 2008; Adrián, 2009; Molero, 2009; Duarte, 2011), se caracterizan por su alto poder de persuasión y reforzamiento ideológico en los grupos sociales de los 
que surgen (Hernández, 2004; Adrián, 2009, 2010; Duarte, 2011, 2013). No obstante, acerca de las redes de metáforas no todo está dicho, porque los aportes realizados por Chumaceiro (2004), Adrián (2009, 2010) o Duarte (2013), parten de diversos enfoques (semánticos, cognitivos o pragmáticos) que no consideran aspectos como las funciones de las redes en la lengua, sus usos estratégicos, o cuáles recursos lingüísticos se les pudieran asociar.

Con base en estos planteamientos, y a fin de dar continuidad a las indagaciones iniciadas en Duarte (2013), el objetivo principal de este artículo es profundizar en el análisis de las funciones estratégicas de las redes de metáforas en el discurso político, porque además, al igual que Bolívar (2007), considero que este tipo de discurso es de los que más influye en la vida de las personas en sociedad, y en él se manifiestan muchas de las estrategias discursivas que usamos cotidianamente para interactuar con los otros. Por esta razón, me concentraré en el discurso del ex presidente Hugo Chávez, quien fue una figura de relevancia y controversia políticas dentro y fuera de Venezuela. Atenderé especialmente a las redes metafóricas urdidas por este emisor en torno al término 'socialismo', ya que este es el modelo impulsado en Venezuela por el propio ex mandatario. Y por último, utilizaré sus intervenciones en el programa Aló Presidente, ${ }^{2}$ en virtud de haber sido un programa caracterizado por su alta difusión y transmisión semanal, en vivo, y emitido a través de varios medios masivos de comunicación (Gualda, 2012), que son atributos que ofrecen la posibilidad de analizar exhaustivamente algunas prácticas sociales, y diversas estrategias políticas, usualmente vertidas en el discurso.

En cuanto al enfoque teórico-metodológico partiré de una perspectiva que se vale de manera crítica del enfoque cognitivo. La tradición conceptual, desde la lingüística cognitiva o la psicolingüística, sostiene que la relación entre la metáfora y su contenido es obvia (Gibbs, 1999; Duarte, 2011). Esto significa que se parte del presupuesto según el cual, las personas tienen un conocimiento tácito e inequívoco de las palabras y sus significados metafóricos, lo cual ha dado lugar a que algunos investigadores descarten de antemano la necesidad de realizar un análisis profundo de las evidencias lingüísticas y contextuales que permitirían dar cuenta de los significados que se privilegian y de los que se restringen en los procesos de metaforización de las palabras. No obstante, en el caso de las redes de metáforas, como evidencia de tales conexiones tendríamos que considerar aquellos fatores que pudieran informar sobre la construcción de sentido y el funcionamiento de las redes en el discurso. Algunos de esos elementos están representados por las diferentes piezas léxicogramaticales (Halliday \& Hasan, 1976; McCarthy, 1990) constituyentes de las redes, además de algunas variables contextuales. Por esta razón, el mejor marco teóricoanalítico debería ser un enfoque mixto que permitiera la integración de la perspectiva semántico-cognitiva de Lakoff y Johnson (2007) y la lingüística (Halliday \& Hasan, 1976; McCarthy, 1990; Halliday, 1994). En este sentido, considero que el Análisis Interaccional del Discurso (AID) de Bolívar (2007) es el enfoque discursivo que 
ofrece la amplitud necesaria para sintetizar de manera óptima tanto el análisis textual como el cognitivo, en función de los factores contextuales. Dicho de otra forma, con base en los planteamientos del AID (Bolívar, 2007), analizaré los datos partiendo de la revisión semántico-cognitiva (Lakoff \& Johnson, 2007), posteriormente, realizaré el examen léxico-gramatical (Halliday \& Hasan, 1976; McCarthy, 1990; Halliday, 1994) de las metáforas y sus redes, y finalmente interpretaré estos resultados.

\section{Fundamentación teórico-metodológica}

Antes de presentar el análisis conviene explicar las bases teóricas que lo sustentarán porque de ellas depende el perfil del método que será utilizado.

\subsection{Redes de metáforas}

Las redes de metáforas son dispositivos pragmáticos del discurso configurados a partir del uso sistemático y continuo de metáforas simples. Por la compatibilidad semántica de las metáforas simples, y a veces por su proximidad textual, pueden ser agrupadas en conjuntos de significados coherentes, que con el tiempo logran adquirir valor simbólico entre los usuarios de la lengua, facilitando la fortificación ideológica de sus contenidos (Duarte, 2013). Esto quiere decir que las redes de metáforas son bloques o familias de significados metafóricos que "estructuran el discurso y que se validan durante la interacción entre el emisor del texto y sus interlocutores 'óptimos' (Duarte, 2013). Las redes de metáforas son construidas por los hablantes durante sus intercambios comunicativos porque son esos los momentos cuando los significados metafóricos compartidos se actualizan y lexicalizan, como ocurrió con la expresión 'socialismo del siglo XXI', difundida por el ex presidente Chávez (Duarte, 2011, 2013).

Las redes de metáforas son núcleos conceptuales que encarnan una taxonomía semántica entre las metáforas simples que las constituyen, y esto les permite funcionar como sinónimos metafóricos. Lo que ocurre entre las metáforas durante la interacción es igual a una relación paradigmática y pragmática en la que sus nexos gramaticales o sintagmáticos quedan trascendidos, porque la organización conceptual de los sentidos metafóricos en las redes, y la interconexión de las metáforas simples, ocurre de forma diversa en el diálogo, a lo largo del intercambio, y también inter-discursivamente. Dicho de otra forma:

"Las metáforas simples funcionan como 'metáforas hipónimas' que forman parte de una metáfora hiperónima' o superordenada, que es una categoría de orden superior, desde el punto de vista semántico. La relación que se establece entre los conceptos metafóricos superordenados con las metáforas hipónimas es semejante a la que, según McCarthy (1990: 21), se da entre campo semántico (que es una noción abstracta), y campo léxico (que es la actualización del campo semántico, respectivamente" (Duarte, 2013: 63). 
Esto quiere decir que la categoría superordenada constituye un campo léxicometafórico superior encargado de designar la carga semántica de la red, y las metáforas subordinadas son categorías léxico-metafóricas que tienden a supeditarse al concepto metafórico superordenado. Cada red de metáforas se configura entonces como un concepto general o de nivel superior, sustentado en un conjunto de palabras o conceptos metafóricos clave (subordinados) que funcionan como sinónimos. Pero así como la lingüística no admite sinonimias absolutas, lo mismo sucede con las metáforas simples (subordinadas). De ahí que los límites que segregan a una red de otra no sean ni precisos ni unívocos, y el contenido semántico que prevalece o se destaca como concepto superordenado en cada red, depende directamente de las variables contextuales que entran en juego durante el intercambio. Por ello se dice que los conceptos metafóricos en las redes se yuxtaponen y se solapan entre sí, y solamente atendiendo a las marcas del co-texto y del contexto puede haber una aproximación al significado más sobresaliente de cada una de ellas (Duarte, 2011, 2013).

\subsection{Análisis Interaccional del Discurso}

El Análisis Interaccional del Discurso (AID) es un enfoque que surge de la Lingüística Sistémica Funcional (LSF) de Halliday (1994), y del análisis del diálogo en la dinámica social (Bolívar, 2007). Supone que el sentido de todo acto discursivo es construido continuamente durante la interacción (Bolívar, 2007), y que los actores del discurso son los responsables de la construcción del texto. Uno de los aspectos determinantes del AID que servirá a nuestro análisis es, precisamente, el que se relaciona con la dimensión interactiva del discurso; primero, porque el sentido de las redes de metáforas es estructurado y organizado durante el intercambio, y por otro lado, porque las redes de metáforas son producto de esa interacción (Bolívar, 2005; Duarte, 2013). Es decir, que las metáforas simples son elegidas a partir de un cierto conjunto de metáforas lexicalizadas (Duarte, 2011), de acuerdo con la efectividad que proporcionan, en potencia o en acto, en el logro de las metas comunicativas de los hablantes. Otro de los planteamientos centrales del AID que asumiré será el de prescindir de la escisión entre gramática y léxico por considerarla artificial. Es decir que, así como la gramática se origina a partir de una serie de selecciones léxicas (Bolívar, 2007), lo mismo sucede con la relación entre las redes de metáforas y las metáforas simples que las constituyen. Esto es, que las primeras resultan de las selecciones léxico-metafóricas de las segundas (Duarte, 2011).

El AID es una perspectiva que requiere que los datos sean analizados, en primera instancia, desde su dimensión textual, observando minuciosamente el comportamiento de los datos lingüísticos en el reconocimiento de las metáforas simples (Lakoff \& Johnson, 2007); en segundo lugar, para el reconocimiento y análisis de las redes de metáforas, se debe observar la dimensión discursiva, entendiendo que esta última está constituida por tres categorías básicas: los participantes de la situación comunicativa, el evento social que enmarca el intercambio, y el texto en sí (Bolívar, 2007). Además del 
análisis léxico-gramatical, el AID precisa la observación y el estudio del contexto, es decir, lo que se dice, cuándo se dice y quién dice qué a quién y en cuáles circunstancias (Halliday, 1994). En palabras de Bolívar (2007: 253):

"El texto [...] se puede describir en dos planos, el de la interacción que se ocupa de la relación entre los participantes, y el autónomo que concierne al registro de la experiencia (Bolívar, 1986, 1994). Ambos planos se construyen en la interacción simultáneamente, pero desde mi perspectiva es el plano interactivo el que determina las opciones en el plano autónomo (porque, por ejemplo, son las personas las que escogen los tópicos en una conversación y no a la inversa)".

Dicho esto, conviene ahora revisar algunos de los conceptos de la LSF que complementarán el análisis y servirán de base para la interpretación de los resultados.

\subsection{Lingüística sistémica funcional y redes de metáforas}

La observación metódica del comportamiento de las redes de metáforas en el discurso político (Duarte, 2011, 2013) a la luz del AID, nos hace pensar que es posible trasladar el análisis desde su dimensión semántico-cognitivo (Lakoff \& Johnson, 2007) a la lingüístico-discursivo (Bolívar, 2007), y estimo que las siguientes nociones y categorías de la LSF (Halliday, 1994) son las más pertinentes para articular este sistema mixto de análisis.

\subsubsection{La cláusula y los complejos clausulares}

Según Halliday (1994), la cláusula es la unidad mínima de análisis en un texto y puede ser definida como, "cualquier segmento del lenguaje centrado alrededor de un grupo verbal"3" (Thompson, 1996: 16). Un ejemplo de cláusula sería "la misión Barrio Adentro es socialismo". Un complejo clausular, en cambio, es:

"una combinación de dos o más cláusulas que da lugar a una unidad mayor, cuya interdependencia normalmente es mostrada a través de señales tan explícitas como las conjunciones" (Thompson, 1996: $194)^{5}$.

Es decir que, los complejos clausulares constan de un conjunto de cláusulas agrupadas en relación paratáctica o hipotáctica entre sí (Halliday, 1994). Veamos ahora un ejemplo del corpus que muestra cómo se crea un complejo clausular a partir de la relación entre sus partes:

\begin{tabular}{|l|l|}
\hline Ejemplo & $\begin{array}{l}{[1] \text { Entonces a toda la clase media, a los sectores populares } \| \text { esto está abierto }} \\
\text { para todos las } 24 \text { horas del día } \| \text { esto no se va a cerrar un solo minuto isaben? } \| Y \\
\text { aqui hay atención bumanista, atención especial-de calidad-para ustedes } \| \text { porque les } \\
\text { amamos y les queremos a todos y a todas } \| \text { Esto es socialismo } \| \text { poner lo social en } \\
\text { primer lugar. (Halliday, 1994: 221). }\end{array}$ \\
\hline
\end{tabular}


Las cláusulas en cursiva muestran la relación paratáctica. Cada una de ellas, independientemente, no requiere de las demás para completar su sentido. Su orden interno solo responde a las elecciones del emisor, y si las reagrupáramos, no alteraríamos su significado. En cambio, las cláusulas que no hemos resaltado se encuentran en relación hipotáctica con el resto del complejo, por lo tanto, para completar su sentido dependen de las cláusulas finitas (las que tienen en su centro un grupo verbal conjugado). Al hacer el ejercicio de reordenamiento de estas cláusulas, pierden todo su sentido y el significado del complejo clausular en conjunto es ostensiblemente transformado.

En toda cláusula, una vez que hemos identificado a los grupos verbales, se puede determinar el tipo de proceso que se está ejecutando, como se explicará a continuación.

\subsubsection{Procesos verbales y marcas léxicas}

Los procesos verbales son los acontecimientos, las acciones, o los estados descritos por los grupos verbales en la cláusula (Thompson, 1996; Martin, Matthiessen \& Painter, 1997). El grupo verbal es el elemento central de los complejos clausulares, y por eso es útil tanto para el reconocimiento de las cláusulas como para la segmentación del texto. Los grupos verbales están conformados por uno o más verbos, así las cláusulas pueden reunirse en torno a grupos verbales que contienen verbos conjugados (en cuyo caso conformarían las denominadas cláusulas principales o finitas) o bien, se reúnen en torno a grupos verbales en gerundio, participio o infinitivo (que son cláusulas no finitas). Casos como el del ejemplo [1]: "Entonces a toda la clase media, a los sectores populares", se denominan cláusulas menores porque no tienen ningún grupo verbal.

Algunos de los procesos siguientes forman parte de los descritos por la LSF (Halliday, 1994), y serán objeto de análisis en el corpus:

a.- Procesos relacionales: implican algún nexo copulativo entre las entidades de la cláusula y los complejos clausulares, y suelen estar representados por los grupos verbales ser/estar y tener;

b.- Procesos materiales: dan cuenta de las acciones verificables que realizan los participantes dentro de la cláusula; y

c.- Procesos mentales: tienen que ver con actividades mentales, de procesamiento consciente y con las emociones (Thompson, 1996; Martin, et al., 1997).

Las marcas léxicas, por su parte, estarán constituidas por las palabras asociadas con las metáforas simples y las redes, ya que explican y documentan sus aspectos semánticos, y además, serán la evidencia de los usos discursivos estratégicos dados por el emisor a las redes. 


\subsection{Aspectos contextuales}

Una vez realizado el reconocimiento de las metáforas simples a partir de la relación entre las señales lingüísticas (palabras vinculadas con 'socialismo'), se debe estudiar el contexto, porque esto permitirá, por un lado, la identificación semántico-pragmática de las metáforas simples, y por otro lado, el reconocimiento de las redes de metáforas y su funcionamiento, siguiendo lo planteado por el AID. Aquí cuando hablemos de contexto nos estaremos refiriendo a la identificación de los participantes del evento de comunicación (emisor y receptores), a la descripción del momento histórico en el cual ocurrió el evento, y además, en qué lugar se encontraban los participantes del intercambio. En muchas oportunidades, estos aspectos, que pueden ser denominados contexto de situación (Firth, 1957; Malinowski, 1984; Halliday, 1994) se encuentran expresados a través de diversas señales lingüísticas que han sido esquematizadas por Halliday (1994) en tres variables de registro, que han sido corroboradas por el AID (Bolívar, 2007), y son las siguientes: el campo (que informa sobre las acciones sociales), el tenor (que indica los roles asumidos por los participantes del intercambio), y el modo (referido a la organización textual).

En los textos, la evidencia relativa a los elementos extra verbales tiene un valor decisivo en la conformación de sentido del discurso y de las redes de metáforas. Una manera de reconocer el contexto de situación, tomando como base las señales lingüísticas, es a través del estudio de los procesos verbales, porque ellos informan sobre las cualidades de la experiencia del mundo que se construye en las cláusulas. Otra manera es a través del estudio de los grados de compromiso, conocimiento y poder con los que el productor textual expresa sus ideas. Es decir, que el emisor podría asumir por completo la responsabilidad de lo que dice o, recurrir al discurso de otros (habla reportada o referida, según Halliday, 1994) para reafirmarlo, o bien mostrar su posicionamiento ante lo que dicen sus interlocutores. Las marcas lingüísticas sobre los grados de compromiso y de conocimiento informan también sobre las ideas que un emisor expone con certeza absoluta o relativa, cuya consecuencia puede ser la asunción de una postura ante los adversarios o la persuasión del auditorio que le es afín.

La construcción del conocimiento compartido entre el emisor y sus interlocutores se fundamenta en las palabras y el uso que se les dé, ya que de ello dependen los mayores o menores grados de certeza sobre lo que se está diciendo, los mayores o menores grados de compromiso sobre lo que se afirma, y los mayores o menores grados de obligación declarados en las cláusulas (Eggins, 1994; Halliday, 1994; Thompson, 1996; Martin, et al., 1997). Esto es así porque el conocimiento y el poder expresados en las palabras están estrechamente relacionados, de ahí que Halliday (1994) y Thompson (1996) hayan hablado de modalización y modulación en las cláusulas, refiriéndose a los grados de modalización del conocimiento, expresados en una escala que da cuenta de la probabilidad de que la información suministrada en la cláusula 
sea cierta o, en una escala que indica cuán frecuentemente lo que se dice sucede así; y los grados de modulación, que se expresan mediante la selección hecha sobre una serie gradual de opciones relacionadas con la capacidad, la disposición, la inclinación o la determinación expresadas en la cláusula. En nuestro caso, y con el propósito de explicitar los resultados, cuando la evidencia lingüística aporte información relacionada con el conocimiento (saber) o con el deber (determinación, capacidad, inclinación), simplemente hablaremos de modalidad epistémica o modalidad deóntica, respectivamente.

La modalidad es un fenómeno frecuentemente asociado a los grupos verbales de los complejos clausulares. Entonces, cuando encontremos marcas de modalidad en los que se detecten metáforas asociadas con 'socialismo', se analizarán los procesos semánticos y pragmáticos porque esto explicaría, como señala el AID (Bolívar, 2007), los tipos de recursos (lingüísticos o discursivos) empleados por el emisor, y podría servir como parte de las señales que justifiquen los manejos estratégicos de las redes de metáforas en el discurso presidencial.

En síntesis, para acceder al reconocimiento y clasificación de las metáforas simples y sus redes, tomaré como base los enfoques semántico-cognitivo y lingüísticogramatical, conjuntamente con el análisis del contexto, que es una propuesta analítica motivada por el AID (Bolívar, 2007). Siguiendo esta misma orientación de análisis combinado, interpretaré los resultados considerando tres niveles equiparables a las metafunciones de la cláusula (Halliday, 1994), a saber: a) el de la realidad que se construye metafóricamente en el discurso cuando el emisor habla de un tópico en particular relacionado con 'socialismo'; b) el nivel interactivo (AID de Bolívar, 2007), que es la relación que establece el emisor con sus interlocutores a partir de las redes de metáforas asociadas con la palabra socialismo y; c) un nivel textual, que describe cómo se organiza la información en las redes de metáforas cuando el término central de comparación es 'socialismo'.

\section{El corpus}

El corpus estuvo constituido por cuatro emisiones del programa Aló Presidente del año 2005, que es el año en el que el ex presidente Chávez comenzó a usar de manera sistemática el término ‘socialismo' en su discurso. La escogencia de estos cuatro programas se supeditó a los siguientes criterios: a. Escogimos los programas en los que Hugo Chávez mencionó mayor número de veces la palabra 'socialismo'. b. Seleccionamos los programas en los que se abordaron los temas privilegiados por el emisor principal, es decir, educación, salud, economía y cultura. Los programas elegidos y sus características contextuales son las siguientes: 
Tabla 1. El corpus.

\begin{tabular}{|c|c|c|}
\hline $\mathbf{N}^{\circ}$ del Programa & Fecha & Lugar de Transmisión \\
\hline 222 & 15.05 .2005 & Liceo Bolivariano del Estado Barinas. \\
\hline 225 & 12.06 .2005 & $\begin{array}{c}\text { Centro de Disgnóstico Integral (CDI) Ma- } \\
\text { turín, Estado Monagas. }\end{array}$ \\
\hline 228 & 10.07 .2005 & $\begin{array}{c}\text { Complejo Cultural Cecilio Acosta en Los } \\
\text { Teques, Estado Miranda. }\end{array}$ \\
\hline 229 & 17.07 .2005 & $\begin{array}{c}\text { Zona Industrial El Piñón, en Cumaná, } \\
\text { Estado Sucre. }\end{array}$ \\
\hline
\end{tabular}

El tema tratado en el programa 222 fue la educación. Por ello la transmisión se realizó desde un liceo bolivariano del Estado Barinas. Los liceos bolivarianos son instituciones de educación básica creadas, en muchos casos, sobre los antiguos liceos venezolanos, que son instituciones públicas en las que se imparte el bachillerato de forma gratuita a la población juvenil. Entre los participantes del programa estuvieron el ministro de educación, otros miembros del entonces gabinete presidencial, algunos militares e invitados barineses adeptos del gobierno. El programa 225 versó principalmente sobre salud pública, y por eso se desarrolló en un Centro de Diagnóstico Integral (CDI), que fue inaugurado por el ex mandatario en ocasión de la emisión de dicho programa desde Maturín. Al programa asistieron los médicos cubanos regentes del CDI, el gobernador del Estado Monagas y algunos invitados, también afectos al gobierno del ex mandatario. El programa 228 se transmitió desde un Centro Cultural del Estado Miranda y estuvo dedicado al tema de la cultura. Entre los asistentes estuvieron algunos representantes de la Misión Cultura y público general de Los Teques, también partidarios del gobierno. El programa 229 tuvo como centro el tema de la economía, y fue transmitido desde una productora de cacao expropiada por el gobierno nacional y re-fundada bajo la figura de 'cooperativa' ${ }^{6}$. Los asistentes al programa fueron, igualmente, algunos ministros, los socios de la cooperativa y público general de la zona que apoyaba la gestión de gobierno del ex presidente.

\section{Categorías y unidades de análisis}

Las categorías que sirvieron para hacer el análisis tienen como base tres dimensiones: una cognitiva, de acuerdo con la teoría de Lakoff y Johnson (2007), para el reconocimiento de las metáforas simples. Otra lingüístico-discursiva, para identificar las redes de metáforas (Halliday \& Hasan, 1976; McCarthy 1990; Duarte 2011), y los contenidos semánticos compartidos y construidos por los participantes del intercambio comunicativo. Y la tercera dimensión que parte del AID, cuya orientación integradora de las diversas corrientes analíticas utilizadas, sirvió para establecer las funciones de las redes de metáforas.

Las unidades de análisis estuvieron constituidas por: el texto global para acceder al reconocimiento de los temas principales de cada programa; los segmentos textuales, 
para identificar las metáforas simples asociadas con 'socialismo'; y los complejos clausulares para el reconocimiento de las redes de metáforas.

El criterio para reconocer las metáforas simples fue léxico: palabras con las que se comparó el término 'socialismo'. Para identificar las redes de metáforas, el criterio fue léxico-discursivo: se prestó atención a las relaciones paradigmáticas y pragmáticas establecidas entre las metáforas simples que determinaron la carga semántica de cada red. En el reconocimiento de las funciones estratégicas de las redes se recurrió a un criterio mixto, determinado por: el aspecto lingüístico y semántico (palabras y significados asociados metafóricamente con 'socialismo'); por el aspecto interaccional, integrado por los participantes del intercambio, sus roles dentro y fuera del discurso y el tipo de realidad que construyen a través del uso de las palabras en las redes; y por el aspecto discursivo relacionado con la organización textual y discursiva de las redes, y el tipo de recursos y estrategias lingüístico-discursivas empleadas por los participantes.

En síntesis, los pasos seguidos fueron:

a. Identificación del tema principal de cada programa.

b. Identificación de los segmentos textuales en los que apareció la palabra 'socialismo'.

c. Análisis de las metáforas asociadas con ‘socialismo’ y sus redes.

d. Análisis de las funciones de las redes y los recursos lingüístico-discursivos empleados en ellas.

\section{Resultados}

Los resultados revelaron 323 metáforas simples asociadas con 'socialismo' que en el corpus se identificaron con 63 ámbitos de la experiencia, como se puede observar en la Tabla 2: 
Tabla 2. Ámbitos de la experiencia asociados con 'socialismo'.

\begin{tabular}{|l|l|l|l|l|l|l|}
\hline Camino & Conducto & Meta & $\begin{array}{l}\text { Edifi- } \\
\text { cación }\end{array}$ & Historia & Batalla & Democracia \\
\hline Revolución & Diálogo & Divulgación & Salud & Cristianismo & Economía & Cooperación \\
\hline Proyecto & Mensaje & Comunidad & Pueblo & Educación & Trabajo & Misión \\
\hline Convenio & Ética & Semiótica & Cultura & Siembra & Familia & Gobierno \\
\hline $\begin{array}{l}\text { Colectivo / } \\
\text { Colectividad }\end{array}$ & Organización & Alfabetización & Naturaleza & Nacimiento & $\begin{array}{l}\text { Humanismo } \\
\text { / Humanidad }\end{array}$ & Vida \\
\hline Hermandad & Valores & Obra & Identidad & $\begin{array}{l}\text { Tópico del } \\
\text { Discurso }\end{array}$ & Proceso & Crecimiento \\
\hline $\begin{array}{l}\text { Igualdad / } \\
\text { Igualar }\end{array}$ & $\begin{array}{l}\text { Inclusión / } \\
\text { Incluir }\end{array}$ & Obligación & Amor & Mandato & Espiritualidad & Concreción \\
\hline Cotidianidad & Imitación & Asistencia & Apertura & Paz & Cambio & Propuesta \\
\hline Justicia & Libertad & Origen & Control & Producción & $\begin{array}{l}\text { Eliminar / } \\
\text { Eliminación }\end{array}$ & Radicalización \\
\hline
\end{tabular}

El cuadro refleja las metáforas simples asociadas directa o indirectamente con 'socialismo', y de estos 63 conceptos metafóricos los que más se destacaron por su alta incidencia en el corpus fueron los siguientes:

Tabla 3. Conceptos metafóricos de mayor incidencia.

\begin{tabular}{|l|c|}
\hline Conceptos metafóricos & Número de veces que aparecieron \\
\hline Socialismo es tópico del discurso & 31 \\
\hline Socialismo es diálogo & 18 \\
\hline Socialismo es edificación & 18 \\
\hline Socialismo es camino & 17 \\
\hline Socialismo es historia & 17 \\
\hline Socialismo es meta & 15 \\
\hline
\end{tabular}

El resto de los conceptos metafóricos apareció 10 veces o menos. Lo destacable es la tendencia de las metáforas simples a agruparse en redes de significados. En este sentido, identifiqué nueve redes de metáforas, cuyos ejemplos más representativos están condesados en el siguiente esquema:

\begin{tabular}{|l|l|}
\hline & Red Verbal \\
\hline $\begin{array}{l}\text { Palabras clave de las } \\
\text { 'metáforas subordi- } \\
\text { nadas' }\end{array}$ & "Socialismo es: tópico / divulgación / mensaje" \\
\hline Ejemplo & $\begin{array}{l}{[2] \text { "El socialismo, el socialismo, no habíamos tocado el }} \\
\text { tema, nos llega por satélite desde allá desde las bases del } \\
\text { pueblo el tema del socialismo". }\end{array}$ \\
\hline
\end{tabular}




\begin{tabular}{|c|c|}
\hline & Red de Conducción \\
\hline $\begin{array}{l}\text { Palabras clave de las } \\
\text { 'metáforas subordi- } \\
\text { nadas' }\end{array}$ & "Socialismo es: camino / meta / orientación" \\
\hline \multirow[t]{2}{*}{ Ejemplo } & $\begin{array}{l}\text { [3] o seguimos destruyendo el planeta por el camino del } \\
\text { capitalismo voraz, que sólo beneficia a una minoría además, } \\
\text { y acaba con bosques, acaba con los recursos naturales, acaba } \\
\text { con la atmósfera para enriquecer a una minoría y para que la } \\
\text { mayoría sea pobre, o construimos el otro camino. ¿Cuál es } \\
\text { el otro? El socialismo, el otro camino es el socialismo, } \\
\text { el socialismo democrático y la revolución democrática es el } \\
\text { camino hacia el socialismo. }\end{array}$ \\
\hline & Red de Concreción \\
\hline $\begin{array}{l}\text { Palabras clave de las } \\
\text { 'metáforas subordi- } \\
\text { nadas' }\end{array}$ & "Socialismo es: edificación / concreción" \\
\hline \multirow[t]{2}{*}{ Ejemplo } & $\begin{array}{l}\text { [4] El socialismo del siglo XXI, el camino para construirlo } \\
\text { es lo que ha llamado Roberto Fernández Retamar, hablado } \\
\text { de la democracia revolucionaria y es lo que aquí nosotros } \\
\text { debemos tener como norte en la brújula, la brújula democ- } \\
\text { racia revolucionaria. }\end{array}$ \\
\hline & Red Religiosa \\
\hline $\begin{array}{l}\text { Palabras clave de las } \\
\text { 'metáforas subordi- } \\
\text { nadas' }\end{array}$ & "Socialismo es: Cristo" \\
\hline \multirow[t]{2}{*}{ Ejemplo } & $\begin{array}{l}\text { [5] Cristo fue un ser humano, pues, Cristo fue un hom- } \\
\text { bre que luchó y era un revolucionario, y si Cristo hubiera } \\
\text { vivido en estos tiempos, como persona de carne y hueso, } \\
\text { entre capitalismo y socialismo no tengo la menor duda de } \\
\text { que sería un socialista radical, Cristo el Redentor, sería un } \\
\text { socialista radical. }\end{array}$ \\
\hline & Red Socialismo Nacional \\
\hline $\begin{array}{l}\text { Palabras clave de las } \\
\text { 'metáforas subordi- } \\
\text { nadas' }\end{array}$ & "Socialismo es: identidad / origen / cultura / historia" \\
\hline \multirow[t]{2}{*}{ Ejemplo } & $\begin{array}{l}\text { [6] ¿cómo vivían los indios? En socialismo, en comuni- } \\
\text { dades, no había capitalismo, los indígenas compartían todo } \\
\text { y comparten todo y tenemos que aprender mucho de la } \\
\text { cultura autóctona originaria, indígena nuestra que está } \\
\text { en nuestras propias raíces. }\end{array}$ \\
\hline & Red de Economía \\
\hline $\begin{array}{l}\text { Palabras clave de las } \\
\text { 'metáforas subordi- } \\
\text { nadas' }\end{array}$ & "Socialismo es: economía / cooperativas" \\
\hline Ejemplo & $\begin{array}{l}\text { [7] El socialismo del siglo XXI, el crédito que les hemos } \\
\text { dado a los trabajadores, a la cooperativa }\end{array}$ \\
\hline
\end{tabular}




\begin{tabular}{|c|c|}
\hline & Red Deóntica \\
\hline $\begin{array}{l}\text { Palabras clave de las } \\
\text { 'metáforas subordi- } \\
\text { nadas' }\end{array}$ & "Socialismo es: obligación" \\
\hline \multirow[t]{2}{*}{ Ejemplo } & $\begin{array}{l}\text { [8] la democracia revolucionaria tiene que caracterizarse } \\
\text { cada día más para que sea de verdad democracia y de verdad } \\
\text { revolucionaria por el gobierno popular, el gobierno popular } \\
\text { en distintos niveles, de distintas formas, la toma de decisio- } \\
\text { nes, el impulso, el control social en lo político, [...] Bueno, } \\
\text { ahí el socialismo, el gobierno popular, tiene que pensarse y } \\
\text { tiene que sembrarse y tiene que activarse en distintos ám- } \\
\text { bitos, distintos niveles, distintos frentes de batallas, distintos } \\
\text { escenarios en lo económico. }\end{array}$ \\
\hline & Red Bélica \\
\hline $\begin{array}{l}\text { Palabras clave de las } \\
\text { 'metáforas subordi- } \\
\text { nadas' }\end{array}$ & "Socialismo es: batalla ideológica" \\
\hline \multirow[t]{2}{*}{ Ejemplo } & $\begin{array}{l}\text { [9] El socialismo concreto, de la construcción, del modelo. } \\
\text { Bueno, un poco... Porque por ahí viene la batalla también, } \\
\text { la batalla ideológica. Hemos decidido antier convocar a } \\
\text { un conjunto, vamos a hacer seminarios para batallar o dar } \\
\text { la batalla ideológica con la idea socialista, los que quieran } \\
\text { saquen su capitalismo pues, saquen el capitalismo para pul- } \\
\text { verizarlos, he dicho, en el debate. }\end{array}$ \\
\hline & Red Democracia Revolucionaria \\
\hline $\begin{array}{l}\text { Palabras clave de las } \\
\text { 'metáforas subordi- } \\
\text { nadas' }\end{array}$ & "Socialismo es: democracia revolucionaria y revolución" \\
\hline Ejemplo & $\begin{array}{l}{[10] \text { Venezuela cambió para siempre, este es el camino de }} \\
\text { la democracia revolucionaria, esto es el socialismo, muy } \\
\text { distinto al capitalismo: perversión capitalista que mercan- } \\
\text { tiliza todo, hasta la vida ¿tú cuánto tienes en dinero? ¿Cuánto } \\
\text { vales? o ¿Cuánto puedes vivir?, incluso. Eso es el capitalismo. }\end{array}$ \\
\hline
\end{tabular}

Los resultados reflejados en el esquema permiten pensar que las redes de metáforas son una tendencia en el discurso político que plantea nuevas relaciones de sentido y nuevos modos de ver la realidad, a partir de los usos estratégicos que el emisor dio a las metáforas simples. Es por ello que se hace necesario un nuevo nivel de análisis que permita interpretar el funcionamiento de las redes en el discurso político, y los usos estratégicos dados por el emisor a este dispositivo discursivo.

\section{Funciones estratégicas de las redes de metáforas}

Analizar los resultados desde un enfoque mixto (gramatical y discursivo), como el sugerido por el AID, permitió, en primer lugar, establecer la relación entre las redes de metáforas con los significados representacionales, interpersonales y textuales (Halliday, 1994) constituidos en ellas. Y con base en el AID (Bolívar, 2007) se realizó la interpretación lingüístico-discursiva de los datos. Esta última perspectiva de análisis condujo a la detección de tres funciones estratégicas de las redes de metáforas. 


\subsection{Función representacional de las redes de metáforas: Representación del 'socialismo'}

Como señala el AID, el plano autónomo del discurso, que es una dimensión elaborada por los participantes del evento comunicativo durante el intercambio (Bolívar, 2007), tiene que ver con el mundo referencial. Es decir, con la manera como los hablantes representan la experiencia sobre el mundo en los textos. De ahí que a partir del análisis lingüístico-discursivo del corpus se pueda colegir cómo es ideado el 'socialismo' a través de las redes de metáforas que se le asocian. Y esto es así porque una de las funciones estratégicas de dichas redes consiste en representar la experiencia del mundo. La prueba lingüística de ello, como aconseja el AID, está contenida en las selecciones léxicas relativas a los grupos verbales que predominaron en las redes, que en muchas ocasiones coincidieron con procesos relacionales y materiales. De este modo, tras el análisis de los datos se puede decir que cuando el emisor comparó 'socialismo' con palabras del campo semántico de la concreción, por ejemplo, lo hizo para despojar al término de su complejidad y abstracción. Veamos:

[11] El socialismo no es algo que esté construido, no, el socialismo es un proceso de todos los días en construcción (red de concreción)

[12] aquí estamos en presencia real y concreta del nuevo socialismo que vamos construyendo paso a paso como única vía para salir del atraso (red de concreción)

Los ejemplos [11] y [12] revelan la presencia de procesos materiales ("esté construido"; "vamos construyendo"; "salir") y relacionales ("no es"; "es"; "estamos"), lo que podría responder al interés del emisor por explicar la palabra 'socialismo' de manera sencilla, concreta y según su propia interpretación. Otra muestra de lo que decimos se encuentra en el ejemplo [10] de la red "democracia revolucionaria", como se observa en el siguiente extracto: "este es el camino de la democracia revolucionaria, esto es el socialismo".

Otros procesos identificados en el corpus son los mentales, sobre todo los que contienen selecciones léxicas relacionadas con miedo, terror, odio y amor, que es cuando las redes de metáforas contienen la contraposición socialismo-capitalismo o imperio-gobierno de Hugo Chávez, por ejemplo:

[13] el amor se multiplica y se desata por todas partes, el odio también se desata, el odio también se pega y el odio destruye, el odio es propio del capitalismo, el amor es propio del socialismo, "amaos los unos a los otros", Cristo era socialista, estoy absolutamente seguro (red religiosa).

Del ejemplo [13] solo resalté los procesos materiales ("multiplica"; "desata"; "pega"; "destruye") y los mentales ("amaos"), y lo que más sobresale es la contraposición socialismo-capitalismo. Esta clase de dicotomías suele plantearse, generalmente, bajo el dominio del campo de las emociones. En el ejemplo [13], aun cuando los procesos 
materiales se encuentran en mayor cantidad, predomina la carga emotiva marcada por los sustantivos "amor" y "odio" que acompañan a dichos procesos.

Esta categoría permite inferir que el emisor busca construir una noción de ‘socialismo' simple, sencilla y de fácil comprensión para todos, pero lo suficientemente amplia y, si se quiere, errática como para no fijar un solo sentido, lo que le permitiría ajustar el significado del término a los intereses de cada momento. Además, la tendencia es plantear la palabra 'socialismo' en términos emotivos, que es una evidente estrategia de persuasión (Perelman \& Olbrechts-Tyteca, 1969; Aristótles, 1990) para atraer más a sus adeptos, para ganar más adhesiones y para fijar distancia ante el adversario político.

\subsection{Funcióninterpersonaldelasredes de metáforas: Interacción con los interlocutores}

El interactivo es otro de los planos para el análisis textual propuesto por el AID. Se trata de una dimensión particularmente interesante que permite dilucidar la función interpersonal de las redes de metáforas, a través del análisis de las relaciones elaboradas discursivamente entre los participantes del intercambio. Esta categoría se conforma, según se corrobora en el corpus, por redes en las que figuran distintas estrategias construidas interactivamente para lograr algunos propósitos de comunicación identificables con el emisor. Veamos los ejemplos:

[14] Yo invito a todos los gobernadores, a todos los alcaldes del país a seguir el ejemplo bueno de Ramón Martínez y de los alcaldes del estado Sucre, y de los productores que vamos asociándonos en cooperativas. Y esto es socialismo, ya lo decía Samuel Contreras, el socialismo del siglo XXI (red deóntica)

En el ejemplo [14] marcamos las palabras que señalan modalidad deóntica. La evidencia demostró que el ‘socialismo' está planteado por el emisor principal en términos de obligación, y es de hacer notar que habiendo sido Hugo Chávez una figura de autoridad, no parece ingenua la evaluación positiva de la segunda frase, “seguir el ejemplo bueno", porque con ello se enfatiza que la manera señalada por él era la forma correcta de 'socialismo' que se debió establecer en Venezuela. Otro ejemplo en el que se manifiesta la modalidad deóntica es:

[15] la democracia revolucionaria tiene que caracterizarse cada día más para que
sea de verdad democracia y de verdad revolucionaria por el gobierno popular, el
gobierno popular en distintos niveles, de distintas formas, la toma de decisiones,
el impulso, el control social en lo político, [...] Bueno, ahí el socialismo, el gobierno
popular, tiene que pensarse y tiene que sembrarse y tiene que activarse en distin-
tos ámbitos, distintos niveles, distintos frentes de batallas, distintos escenarios en lo
económico (red deóntica)


La evidencia en el ejemplo [15] registra que entre los conceptos que se subordinan a "socialismo es obligación" está el de "democracia revolucionaria" y socialismo "es batalla", porque el ejemplo presenta señales que ponen de manifiesto que el mandato es el centro de la red, como ocurre con el ejemplo [14]. Además, un fenómeno recurrente en la red deóntica es que la obligación está gramaticalizada, lo que le da al grupo metafórico mayor fuerza como recurso retórico para la persuasión del auditorio.

Otra estrategia muy utilizada por el emisor, que sirve para identificar la relación que establece con sus interlocutores, es la expresión de certeza absoluta, como se aprecia en el ejemplo que sigue:

[16] El proyecto de Cristo yo no tengo dudas y en la medida en que más leo a Cristo su palabra directa, no las interpretaciones que algunos hacen; no, su palabra directa la palabra de Cristo y la obra de Cristo no tengo dudas de que el proyecto capitalista es el de Judas y el proyecto de Cristo es el mismo de Bolívar y es el nuestro es el camino a un socialismo del Siglo XXI que es el que estamos comenzando a construir (red religiosa)

En el ejemplo [16] sobresale la modalidad epistémica y la contraposición entre socialismo y capitalismo en términos de dicotomía religiosa. Aquí la imagen que el emisor edifica de sí es la de conocedor experto de lo que él mismo expresa como "palabra de Cristo". Por lo tanto, se colige que sus interpretaciones son las válidas. Estos ejemplos permiten pensar que el emisor, por una parte, consolida su imagen de autoridad cuando plantea el 'socialismo' en términos de obligación, y por otra parte, se erige como voz autorizada para interpretar cualquier mensaje aparentemente cristiano, que considere propicio para defender el ‘socialismo' que propone.

\subsection{Función metadiscursiva de las redes de metáforas: El texto en sí y el 'socialismo' como tópico}

El AID (Bolívar, 2007) es un enfoque que plantea la posibilidad de articular el análisis semántico-cognitivo, el propiamente lingüístico y el contextual. La amplia visión de análisis que el AID facilita es por lo que se ha podido detectar la tercera función de las redes de metáforas, que está vinculada con el texto en sí y con el 'socialismo' como tema. Y es que esta última categoría se relaciona con la organización textual, y en ella convergen todas selecciones de metáforas que aglutinadas discursivamente en redes colocan al 'socialismo' en el foco de la discusión, o como término que se está definiendo. En este sentido, uno de los recursos lingüísticos más importante que identifiqué fue el uso de la palabra 'socialismo' como estrategia sintáctico-gramatical, es decir que mediante el uso de expresiones indexicales se dan sustituciones léxicopronominales para definir lo que es el 'socialismo', y los deícticos se presentan en relación anafórica o catafórica con 'socialismo', como muestran los ejemplos: 
[17] Ah, pero entonces la perversión del imperio y sus lacayos, está tratando de fortalecer o de crear la idea de que el socialismo que Chávez ha propuesto, bueno ya Chávez se definió te das cuenta, prefieres tu el socialismo que Chávez propone o la democracia. Entonces mucha gente pudiera caer por inocente y por eso es que la batalla ideológica es de todos los días gobernadores, alcaldes, diputados, muchachos; ustedes en ese trabajo los Liceos Bolivarianos tienen que ser un centro de formación de republicanos bolivarianos como lo plantea el término como decía Simón Rodríguez y eso es socialismo. (red bélica)

En el ejemplo [17], la marca deíctica funciona claramente como catáfora en la definición metafórica de 'socialismo'. Pero también hay ejemplos en los que la marca indexical es anafórica y catafórica al mismo tiempo, como ocurre con los siguientes ejemplos: el [1] ("les amamos y les queremos a todos y a todas. Esto es socialismo, poner lo social en primer lugar"); y el [14] ("vamos asociándonos en cooperativas. Y esto es socialismo, ya lo decía Samuel Contreras, el socialismo del siglo XXI"). Estos ejemplos demuestran cómo la expresión "esto es socialismo" está referida al texto que le precede (catáfora) y al que viene después (anáfora), probablemente como un recurso retórico de reforzamiento de la definición que el emisor principal desea establecer en ese momento.

Otra estrategia del discurso identificada en el corpus fue el "habla referida", que en este caso consistió en definir al 'socialismo' utilizando las voces de otros. El habla referida se reconoció en los momentos en los que el emisor principal nombró y recomendó algún tipo de literatura sobre el socialismo; también, cuando citó, explicó, y se apropió de frases sobre 'socialismo' dichas por otras personas; o simplemente cuando acunó alguna palabra que estimó vinculable con el término en cuestión. Esto último se puede observar a continuación:

[18] He ahí otro ataque, el ataque ideológico por donde viene el adversario. Están tratando de manipular el tema del socialismo. Aquí está vean ustedes no es casualidad que hoy domingo El Universal mire yo esta mañana lo subrayé aquí está el ataque clarito, clarito [...]. Primera noticia aquí arriba, PDVSA camina hacia el desastre inevitable (red bélica)

El [18] es un ejemplo de cómo el emisor realizó una cita al diario venezolano El Universal, con el propósito de "contraatacar" a los que, según él mismo definió, eran los adversarios de su gestión, que en este ejemplo están representados por los dueños del diario. Otros ejemplos muestran la constante apelación a la emoción, que en tanto recurso retórico persigue, por una parte, la identificación del auditorio con el 'socialismo' que el emisor principal propone, y por otra, infundir rechazo y temor hacia lo que el emisor coloca como contrario al 'socialismo', que como se ha dicho es el imperio o el capitalismo: 
[19] El socialismo es el camino a la vida, es el camino a la igualdad, es lo que dijo Cristo, vuelvo a insistir en el mensaje de Cristo, el Padre Redentor, "Amaos los unos a los otros" el socialismo es el camino del amor. (red religiosa) [20] Los que quieran ir con Judas al infierno, váyanse por el capitalismo; los que queramos ir con Cristo por la vía de la construcción del reino de Dios aquí en la tierra, es decir, la igualdad y la libertad, vámonos por el socialismo!, ¡eso es! (red religiosa)

En estos ejemplos el registro pertenece al campo de la religión porque los elementos léxicos privilegiados se relacionan con cristianismo. En el ejemplo [19] el emisor colocó camino, amor y cristianismo en el mismo campo semántico de 'socialismo', y éste es el único caso del corpus donde "socialismo es vida". En el ejemplo [20] observamos que el superordenado "religión" subordina a los contenidos conceptuales relativos a movimiento, concreción, e incluso igualdad y libertad con quienes lo religioso se relacionó directamente; nótese también que en la contraposición entre capitalismo y 'socialismo' las evaluaciones de capitalismo son negativas, al igual que la carga afectiva, mientras que ocurrió lo contrario cuando el emisor se refirió a 'socialismo'. Añadiré además, que dicha contraposición, repetida a lo largo del corpus en distintas redes, pone en evidencia el uso de un recurso retórico denominado falacia de apelación a un falso dilema, que consiste en oponer dos alternativas como excluyentes entre sí (socialismo-capitalismo) obviando la existencia de otras posibles opciones ${ }^{7}$.

La evidencia hallada en el corpus da razones para creer que es probable que el uso del habla referida no sea para dar mayor credibilidad al discurso del emisor principal, sino más bien, para autorizar (o desautorizar) y legitimar (o deslegitimar) las opiniones, escritos y declaraciones de los otros, según sean sus seguidores o sus adversarios. Este último recurso, además, sirvió para que el emisor se acercara a sus seguidores y tomara distancia de sus opositores.

\section{CONCLUSIÓN}

Las redes de metáforas, al igual que sus componentes, las metáforas simples, son dispositivos cognitivos que tienden a estandarizarse, normalizarse y lexicalizarse dentro de las comunidades lingüísticas que las producen, como se expuso a lo largo de este trabajo. En el análisis del corpus, los resultados revelaron que las redes de metáforas surgen del uso estratégico dado por el emisor principal a las metáforas simples en torno a 'socialismo'. Asimismo, se demostró que la tendencia de las metáforas simples a aglutinarse en el discurso político, plantea modos nuevos de concebir y ver la realidad y el mundo que nos rodea. Por otro lado, los resultados evidenciaron que el comportamiento sistemático de las redes requería una exploración más exhaustiva y amplia lo cual condujo a la adopción de un sistema analítico e interpretativo dual (semático-cognitivo y lingüístico) que incorporara también el análisis del contexto, como sugiere el AID. Al proceder de esta manera se pudo 
constatar que como dispositivo metafórico del lenguaje, las redes cumplen con tres funciones estratégicas concomitantes y articuladas entre sí, al servicio de propósitos comunicativos identificables con el emisor principal. Dichas funciones estratégicas de las redes de metáforas son: la representacional; la interpersonal; y la metadiscursiva. El reconocimiento de estas funciones permitió la aproximación al significado de la experiencia del mundo construida por el emisor principal desde la noción metafórica de ‘socialismo'. Esto se interpretó como un intento de dar simplicidad y concreción al término sin comprometerse con una definición definitiva, sino más bien aportando una que se fuese ajustando a las circunstancias, y probablemente a los intereses del productor textual. La función interpersonal nos dio acceso a la imagen de sí construida discursivamente por el emisor ante sus interlocutores 'óptimos', tomando la palabra 'socialismo' como foco en el intercambio. Con ello se demostró que la modalidad epistémica de certeza absoluta y la obligación gramaticalizada funcionan para demandar una reacción inmediata y positiva de los adeptos con respecto a la ejecución del 'socialismo', y también para afianzar al emisor como figura de autoridad, a la que hay que creer, seguir y obedecer sin cuestionamientos. La función metadiscursiva develó, a través de la organización de la información metafórica en torno a 'socialismo', que entre los recursos lingüísticos utilizados por el emisor de manera sobresaliente estuvieron las frases indexicales (esto/eso es socialismo), lo que reforzó la tendencia a definir 'socialismo' de manera llana y según su propia visión; pero además, fue un recurso retórico que al repetirse una y otra vez a lo largo del corpus, enmarcó al término en una especie de 'letanía' o 'coro', que hacía más penetrante las frases que lo contenían y, por lo tanto, más fáciles de recordar por los interlocutores óptimos. Asimismo, la función metadiscursiva permitió la identificación del uso de la falacia de falsa bifurcación, que estuvo presente en todas las redes en las que el emisor confrontó al 'socialismo' contra el capitalismo, o a su gestión de gobierno contra lo que él denominaba el imperio. Esta función también permitió determinar que la estrategia del discurso identificada como habla referida se utilizó indistintamente para que el emisor se acercara más a sus partidarios y se alejara más de sus oponentes, a través de la legitimación de otros discursos que consideró adecuados para la definición de su 'socialismo', así como la deslegitimación de todo aquello que consideró contrario. Finalmente, podríamos decir que las redes de metáforas en el discurso político, a través de sus funciones estratégicas, sugerirían que están constituidas por un gran potencial ideológico y persuasivo en el discurso político que propone nuevos retos por investigar a los Estudios del Discurso. 


\section{REFERENCIAS BIBLIOGRÁFICAS}

Adrián, T. (2009). La metaforización en el discurso político venezolano: Rómulo Betancourty Hugo Chávez: Tesis doctoral, Universidad Pedagógica Experimental LibertadorInstituto Pedagógico de Caracas, Venezuela.

Adrián, T. (2010). La metáfora conceptual en el discurso político venezolano: Rómulo Betancourt y Hugo Chávez Frías. Revista de la Asociación Latinoamericana de Estudios del Discurso, 10(1), 9-33.

Aponte Moreno, M. (2008). Metaphors in Hugo Chavez's Political Discourse: Conceptulizing Nation, Revolution and Opposition. Tesis doctoral, Unviversidad de Nueva York, Nueva York, Estados Unidos de América.

Aristóteles (1990). Retórica. Madrid: Biblioteca Clásica Gredos.

Bolívar, A. (2003). Nuevos géneros discursivos en la política: El caso de Aló Presidente. En L. Berardi (Comp.), Análisis crítico del discurso. Perspectivas latinoamericanas (pp.101-130). Santiago: Frasis Editores.

Bolívar, A. (2005). Discurso e interacción en el texto escrito. Caracas: Consejo de Desarrollo Científico y Humanístico. Universidad Central de Venezuela.

Bolívar, A. (2007). El análisis interaccional del discurso: Del texto a la dinámica social. En A. Bolívar (Comp.), Análisis del discurso. ¿Por qué y para qué? (pp.247-277). Caracas: Editorial CEC, S.A., Los Libros de El Nacional y la Universidad Central de Venezuela.

Chilton, P. \& Ilyin, M.V. (1993). Metaphor in political discourse: The case of the 'Common European House'. Discourse and Society, 4(1), 7-31.

Chumaceiro, I. (2004). Las metáforas políticas en el discurso de dos líderes venezolanos: H. Chávez \& E. Mendoza. Revista Latinoamericana de Estudios del Discurso, 4(2), 91-113.

Duarte, M. (2011). Las metáforas cognitivas en torno a la noción de 'socialismo' en Aló Presidente. Tesis de magíster, Universidad Central de Venezuela, Caracas, Venezuela.

Duarte, M. (2013). Redes de metáforas cognitivas en el discurso político: “El socialismo del siglo XXI" de Hugo Chávez. Revista Latinoamericana de Estudios del Discurso, 13(1), 57-77.

Eggins, S. (1994). An introduction to systemic functional linguistics. Londres: Printer Publishers.

Firth, R. (1957). Hombre y cultura. México: Editorial Siglo XXI. 
García Damborenea, R. (2005). Diccionario de falacias. En uso de razón [en línea]. Disponible en: www.usoderazon.com

Gibbs, R. (1999). Researching metaphor. En L. Cameron \& G. Low (Eds.), Researching and Appalying Metaphor (pp. 29-47). Cambridge: Cambridge University Press.

Gualda, R. (2012). The discourse of Hugo Chavez in Aló Presidente: Establishing the Bolivarian revolution through television performance. Tesis doctoral, Universidad de Austin, Texas, Estados Unidos de América.

Halliday, M. A. K. (1994). An introduction to functional grammar. Londres: Edward Arnold.

Halliday, M. A. K. \& Hasan, R. (1976). Cohesion in English. Londres: Longman.

Hernández, M. L. (2004). La metáfora política en la prensa venezolana: Un estudio lingüístico cognitivo. Opción Revista de Ciencias Humanas y Sociales, 20(44), 5577 [en línea]. Disponible en http://www.scielo.org.ve/scielo.php?script=sci_ arttext\&pid=S1012-15872004000200004\&lng $=$ es\&nrm=iso

Lakoff, G. \& Johnson, M. (2007). Metáforas de la vida cotidiana. Madrid: Ediciones Cátedra.

Malinowski, B. (1984). El problema del significado en las lenguas primitivas. En Ch. Ogden \& I. Richards (Eds.), El significado del significado (pp. 310-352). Barcelona: Paidós.

Martin, J. R., Matthiessen, Ch. \& Painter, C. (1997). Functional grammar. Londres: Arnold.

McCarthy, M. (1990). Vocabulary. Oxford: Oxford University Press.

Molero, L. (2009). La metáfora en el discurso político venezolano. En M. Shiro, P. Bentivoglio \& F. D. Erlich (Comps.), Haciendo discurso. Homenaje a Adriana Bolivar (pp. 305-332). Caracas: Comisión de Estudios de Postgrado y Facultad de Humanidades y Educación de la Universidad Central de Venezuela.

Moreno Lara, M. A. (2005). La metáfora conceptual y el lenguaje político periodístico. Configuración, interacciones y niveles de descripción. Tesis doctoral, Universidad de la Rioja, España [en línea]. Disponible en: http://dialnet.unirioja.es/servlet/ tesis?codigo $=114$

Perelman, Ch. \& Olbrechts-Tyteca, L. (1969). The new rethoric: A treatise on argumentation. Notre Dame: Notre Dame University Press.

Thompson, G. (1996). Introducing Functional Grammar. Londres: Arnold. 


\section{NOTAS}

1 Para este estudio se utilizaron las transcripciones de los programas Aló Presidente disponibles en la página electrónica del Ministerio de Comunicación e Información (Minci), y están disponibles en: http://alopresidente.gob.ve/transcripciones/

2 Aló Presidente es considerado un nuevo género de discurso en el campo político como se demuestra en Bolívar (2003).

3 Mi traducción. Original en inglés: "any stretch of language centred around a verbal group".

4 El grupo verbal (es) alrededor del cual se organiza la cláusula está en cursiva.

5 Mi traducción. Original en inglés: "a combination of two or more clauses into a larger unit, with their interdependence normally shown by explicit signals such as conjunctions".

6 Por "cooperativa" entendemos un tipo de organización económica constituida por un grupo de personas que se asocia libremente para producir bienes y servicios. Las cooperativas prescriben que cada uno de sus miembros obtiene beneficios y asume riesgos y responsabilidades en igualdad de condiciones.

7 Sobre falacia de la falsa bifurcación o de falso dilema se puede consultar el Diccionario de Falacias (García Damborenea, 2005). 